\title{
Implementation of the Strategy: Problems and Solutions
}

\author{
Yashin N.S. a \\ Andreeva T.A. ${ }^{b}$ \\ Serebrjakov A.V. c \\ Bagautdinova N.G. d \\ ab Russian Economic University named G.V. Plekhanov, Saratov Social and Economic Institute, Saratov, Russia, 410003 \\ c SSTU named Yuri Gagarin, Engels Technological Institute (branch), Engels, Russia, 413100 \\ ${ }^{d}$ Kazan Federal University, Institute of Management, Economics and Finance, Kazan, 420008, Russia
}

\section{Doi:10.5901/mjss.2015.v6n1s3p475}

\section{Abstract}

The paper deals with the implementation of the strategy as a key element of the strategic process. Developed organizational and management mechanism of the process of implementation of the strategy involves the exercise of choice of methods and resources management in accordance with the nature of the factors of internal processes (capacity) of the enterprise and the external environment in which it operates, and to exercise control on the basis of information on the implementation of the organization's processes and stakeholder satisfaction in accordance with the principles of quality management. To evaluate the effectiveness of the implementation of a procedure for strategic verification. Statistical processing of the data obtained by the method of rank correlation has identified strategic indicators, most affecting the level of strategic impact. Integrated use of expert and mathematical processing of information provides a more complete picture of the impact of the implementation of the strategy.

Keywords: strategy, implementation strategy, the effectiveness of implementation

\section{Introduction}

Process of strategic management, from beginning of working out of strategy till its successfully realization - long enough and laborious. Many organisations owing to a considerable quantity of the objective and subjective reasons find it difficult to pass it successfully. Under the different researches, only from 20 to $40 \%$ of the organisations successfully and in full realise the planned strategy and receive desirable results. The reasons such «strategic rupture» (not conformity of actual results of realisation of strategy to strategic target indicators) increasingly become object of scientific researches [7, p.5].

To problems of successful realisation of strategy and revealing of factors of occurrence of «strategic rupture» in different years many domestic foreign scientists were engaged $[1,3-4,10]$. However such questions as process of implementation of strategy, control over its realisation, estimations of implementation are less clear and are understandable, than problems of the strategic analysis, the formulation and choose of a strategy: «all have well learnt to plan, but very few people is able to make» $[1$, p. 3].

\section{Essence, Principles, the Mechanism of Implementation the Strategy}

The variety of approaches to a problem of successful implementation the strategy has defined necessity of working out of the effective mechanism of implementation. Implementation of strategy can be structured on three interconnected stages: directly realisation of strategy, monitoring of results and strategy updating. The methodology successful implementation defines necessity of working out of principles, a choice of necessary means and methods of realisation of this process and working out of methodical recommendations about its realisation (tab. 1). Active integration in instrumental and methodical plan of strategic management and quality management will allow to achieve synergetic effect and steady success of the organisation in long-term prospect. 
Table 1. Methodology of complex system of implementation the strategy

\begin{tabular}{|c|c|c|}
\hline \multicolumn{3}{|c|}{$\begin{array}{c}\text { Implementation of the strategy - process of realisation of strategic plans, monitoring of their realisation and correcting (adjusting) actions for process } \\
\text { optimisation of implementation }\end{array}$} \\
\hline $\begin{array}{c}\text { The } \\
\text { purpose }\end{array}$ & \multicolumn{2}{|c|}{ Achievement of strategic targets of the organisation } \\
\hline Key steps & Principles & Tools \\
\hline Realisation & $\begin{array}{l}\text { Leadership of the head, personnel involving, the } \\
\text { process approach, mutually advantageous relations } \\
\text { with suppliers, constant perfection }\end{array}$ & $\begin{array}{l}\text { Qualitative expansion of plans, structure of splitting of works, network } \\
\text { schedules, the business plan, the process approach, } 6 \sigma \text {, kaizen, TPM, quality } \\
\text { mugs, } 5 \mathrm{~S} \text {, Kanban, the Gant's diagram, QFD, FMEA, procedure PPAP }\end{array}$ \\
\hline Monitoring & $\begin{array}{l}\text { Regularity, the system approach, decision-making } \\
\text { factual }\end{array}$ & $\begin{array}{l}\text { System of the balanced strategic indicators, strategic audit, internal audit, self- } \\
\text { estimation, methods of the comparative analysis, statistical quality monitoring of } \\
\text { quality, self-estimation, audit competitions on quality }\end{array}$ \\
\hline Updating & Leadership of the head, efficiency, constant perfection & $\begin{array}{l}\text { Analytical and expert methods of an estimation, the FMEA-analysis, FCA } \\
\text { method, etc. }\end{array}$ \\
\hline
\end{tabular}

Considering a complex of problems which is necessary for solving in a course of implementation the strategy (scheduling, definition of economic levers and the stimulus used in practice of a management; formation of organizational structure, methods and style of work of directing bodies; realisation of various forms of participation of the personnel in production management), under the implementation of strategy authors understand the integrated multilevel system of forms and methods of influence as the mechanism for achievement of the established purpose, on factors on which condition the result of activity of operated object, namely, result of implementation of strategy depends.

At construction of differentiated (i.e. changing depending on initial and current factors and operating conditions) schemes of the organizational-administrative mechanism of implementation the strategy all uncountable set of factors influencing this process we will unite in two classification groupings: factors of internal processes (potential) of the enterprise and environmental conditions in which it functions (fig. 2). Similar division helps to organise more accurately process of realisation of strategy, but also to take measures on elimination of some negative influences.

To start action of the given mechanism, strategy of the company which realize, taking into account of available internal possibilities and external conditions, and is materialised in concrete results of activity - the fact sheet on realisation is initial developed on a stage of planning. At detection of deviations at an analysis stage of the data received as a result of monitoring action of forces in the block of comparison with target indicators begins and there is a decisionmaking concerning correcting influences.

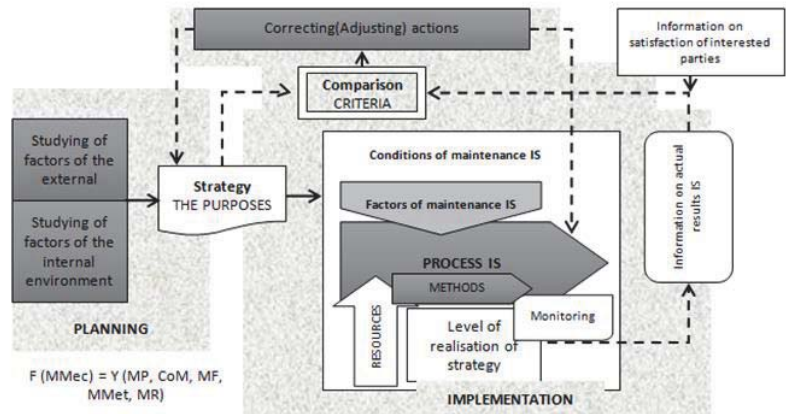

MMec - the management mechanism; MP - the management purposes; CoM - criteria of management; MF - management factors; MMet - management methods; MR - management resources

Fig. 2. The differential scheme of the organizational-administrative mechanism of implementation the strategy (IS)

One of problem places in effective implementation of strategy which have been designated in the beginning of discussion beginning - an effective translation of target strategic reference points from the higher hierarchical levels of strategic management on levels of business units and divisions of the enterprises. It is a problem zone of such functions of management, as the organisation and motivation. One of innovative approaches for the decision of problems «expansions of a policy and the purposes», known in world practice and borrowed from systems of quality management and economical manufacture is the methodology of Hosin Kanri, in which basis the multidimensional X-matrix in which four fields allow to establish correlation interrelation between various categories (strategic target reference points, tactical ways of realisation of strategy, concrete processes and concrete indicators, i.e. results of realisation of strategic plans). Expansion of the basic strategic targets established at the level of the state, the branch ministries, the corporate center and the enterprises entering into it is offered to carry out by means of the cascade of X-matrixes and method «catch a ball» which means process of the coordination of plans «from above - downwards» and «from below - upwards» [9, p. 117]. 


\section{Technique and Results of an Estimation of Productivity Имплементации Strategy}

The key element which is responsible for productivity of process of implementation the strategy is monitoring (supervision continuous process), and consequently and for necessity of its updating on the higher and the average levels of hierarchy of the oil and gas companies. The rating of strategic productivity can show the fullest and operative picture of results of monitoring. For rating construction are necessary quantitative and quality indicators which characterise the process of implementation of the strategy.

The category «productivity» characterises level of achievement of the purposes. We suggest to treat this category taking into account basic principles of quality management as degree of achievement of the results, to the established strategic indicators which satisfy certain requirements of interested parties and conditions for constant perfection of activity of the organisation create.

Recently appears more and more materials (article, performance, methods) according to productivity of quality management systems (QMS) which are similar to problems of an estimation of level of strategic productivity [8, p. 88], but many of them suffer one lack - they are a little difficult for execution and suppose a wide field for interpretation of an estimation of productivity of QMS.

The program of intracorporate strategic verification is developed for definitions of level of strategic productivity and drawing up of a corresponding rating by the author on the basis of a self-estimation, with application of the adapted criteria of an estimation on the basis of office product EXCEL, promoting reception of as much as possible objective results. Verification according to the standard of GOST R ISO 9000-2005 (items 3.8.4): Confirmation on the basis of representation of objective certificates (3.8.1) that the established requirements (3.1.2) have to be executed [2].

The effective system of verification (within the limits of monitoring) processes of industrial divisions, is extremely actual, as creates atmosphere of competitions between separate economic units in corporation, makes active realisation of achievement of objects in view, helps to reveal «narrow» places in the functioning processes influencing development of the enterprise, helps to carry out a choice of priority directions of development for the purpose of increase of investment appeal and strengthening of trust of the interested.

System of an estimation of strategic productivity, it is offered to construct on the basis of four complex indicators, to corresponding four strategic prospects of development which are detailed by means of concrete indicators of strategic development for each of which the index of productivity (tab. 2) is defined. As indicators of strategic productivity (SP) we will understand the generalised strategic target indicator, representing set of the balanced strategic indicators on one strategic prospect.

Table 2. System of an estimation strategic productivity*

\begin{tabular}{|c|c|c|c|c|}
\hline The indicator name & $\begin{array}{l}\text { The plan for the } \\
\text { accounting period }\left(P_{p}\right)\end{array}$ & $\begin{array}{l}\text { Actual indicators for the } \\
\text { accounting period }\left(P_{\mathrm{ai}}\right)\end{array}$ & $\begin{array}{l}\mathrm{P} i j=\mathrm{P}_{\mathrm{a}} / \mathrm{Pp}_{\mathrm{p}} \\
\text { Index SP }\end{array}$ & $\begin{array}{l}\text { Normalised estimation } \\
\text { of index SP (points) }\end{array}$ \\
\hline \multicolumn{5}{|c|}{ The indicator - Consolidation and development gas distribution actives } \\
\hline Extent of served gas pipelines, thousand in km. & 2,87 & 2,89 & 1,01 & 3 \\
\hline Registration of gas pipelines in the property, thousand in $\mathrm{km}$. & 2,44 & 2,44 & 1,00 & 2 \\
\hline The size of participation in supervised organisations, million rbl. & 0,01 & 0,01 & 1,00 & 2 \\
\hline Share of participation in controllable societies, $\%$ & 100,00 & 100,00 & 1,00 & 2 \\
\hline Extent of gas pipelines, thousand in $\mathrm{km}$. & 2,73 & 2,73 & 1,00 & 2 \\
\hline Average percent of deterioration of actives GDS, $\%$ ** & 69,70 & 69,70 & 1,00 & 1 \\
\hline $\begin{array}{l}\text { Total amount of investments in actives GDS under the investment } \\
\text { program, million rbl. }\end{array}$ & 15,07 & 19,27 & 1,28 & 3 \\
\hline Cost of actives GDS, million rbl. & 542,22 & 540,19 & 1,00 & 1 \\
\hline Total value $\mathrm{SP}$ on indicator $\mathrm{SP}_{\text {consol }}$ & & & & 16 \\
\hline \multicolumn{5}{|l|}{ The indicator - Economic efficiency of activity } \\
\hline Net wealth, million rbl. & 682,00 & 752,93 & 1,10 & 3 \\
\hline Net profit, million rbl. & 5,97 & 24,85 & 4,16 & 3 \\
\hline Incomes of other kinds of activity, million rbl. & 609,16 & 616,95 & 1,01 & 3 \\
\hline $\begin{array}{l}\text { The cost price of realised production (services) in other } \\
\text { kinds of activity, million rbl. *** }\end{array}$ & 400,39 & 413,62 & 1,03 & 0 \\
\hline $\begin{array}{l}\text { Administrative and general business expenses by other } \\
\text { kinds of activity, million rbl. }\end{array}$ & 125,83 & 130,75 & 1,04 & 0 \\
\hline Profit by other kinds of activity, million rbl. & 82,95 & 72,59 & 0,88 & 1 \\
\hline About Total value SP on indicator SPeffect & & & & 10 \\
\hline
\end{tabular}


Indexes of strategic productivity $(\mathrm{P} i j)$ Is the relative size showing, in how many time actual indicators of development differ from level of planned targets:

$$
\mathrm{P} i j=\frac{P j f}{P j p^{\prime}}(1)
$$

Where $P_{\mathrm{jf}}, \mathrm{P}_{\mathrm{jp}}$ - the actual and planned data of the indicator characterising -j an index of productivity; $-\mathrm{i}$ - serial number of indicators; $j$ - serial number of indexes of productivity of each indicator. The automatic system of rationing of the received values of indexes is developed for all groups of indicators.

By the offered technique of intracorporate strategic verification the estimation of activity of a part Open Societies «Saratovoblgaz» 16 SaA for 2012 has been carried out. In quality the visualisation tools, the received data such tool as the alarm map consisting of the total table, containing colour indication of results and the histogram reflecting a rating of strategic productivity (suggested to enter fig. 2). Drawing up of a rating of strategic productivity of each economic unit and corporation, as a whole, will give the chance to estimate its contribution to achievement of strategic indicators of corporation, will allow to reveal the most successful regional companies which can be attractive to investors, and also will concentrate attention of a management to updating of activity of the inefficient companies.

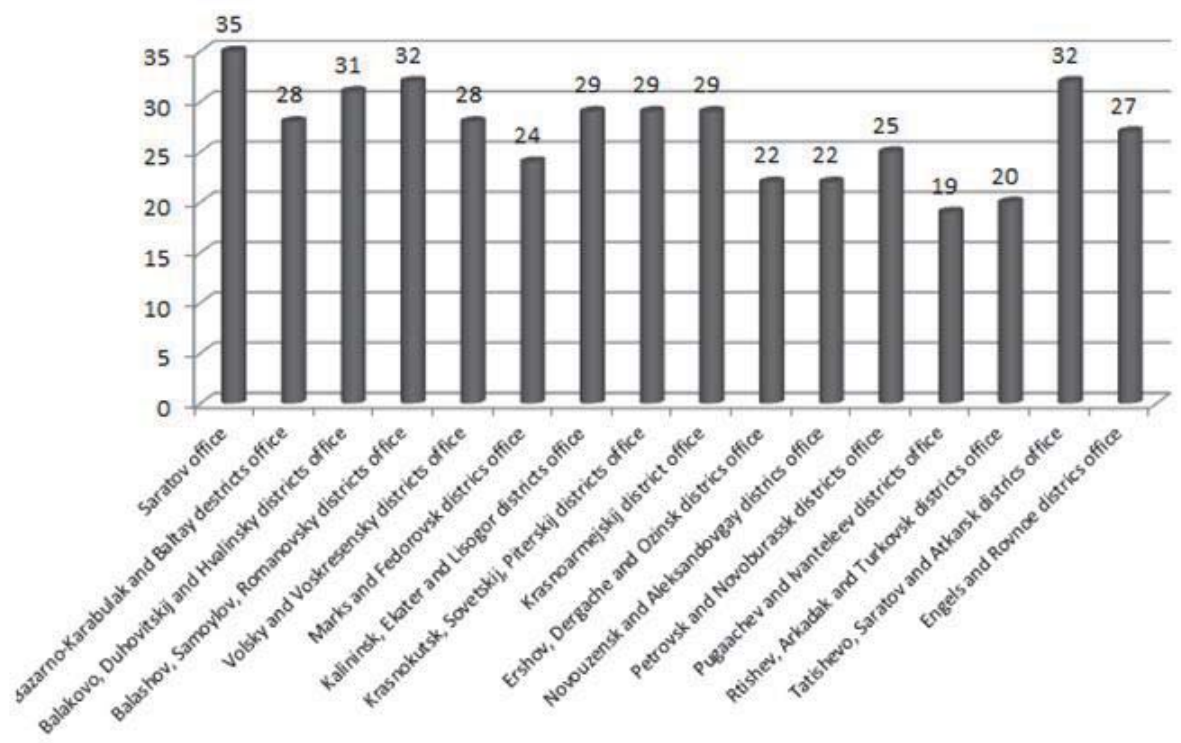

Fig. 2. A rating of strategic productivity of Open Society «Saratovoblgaz» for 2012

By means of a rating of strategic productivity it is possible to display only degree of approach of current activity to an ideal mode. However remains not analyzed what indicators (so what kinds of activity) and in what degree influence increase or decrease in level of productivity. Therefore a following evaluation stage of productivity implementation of the strategy is revealing of the indicators, making the greatest negative impact on result and demanding improvement. For this purpose we will carry out procedure of the statistical analysis of communications between factorial and productive signs of statistical set. Statistical data processing is spent on the basis of a method rank correlations. Were used selective factor of rank correlations of Spirmen (3): ${ }^{p=1-6 \frac{\sum d_{k}^{2}}{n^{3}-n}}$

In which $-d_{k}^{2}$ squares of differences of ranks of each pair compared values, $n$ - sample volume;

And also selective factor of rank correlations of Kendall (3):

$$
\tau=2 \frac{P-Q}{n^{2}-n},
$$

In which $P, Q$ - accordingly number of positive and negative inversions of ranks, $n$ - sample volume. In a case when the statistical importance of correlation communication proved to be true both for factor (2), and for factor (3), specification of factor of Spirmen taking into account repeating ranks [6, p. 56].

Rank correlation between indexes of achievement of planned targets and a deviation of actual level of strategic productivity of division from the level corresponding to planned targets is investigated. Calculation of critical values is spent at a significance value 0,05 . As the basic statistical hypothesis absence of significant correlation communication 
was accepted. Thus, presence of significant correlation communication was shown in a case when value of selective factor exceeded corresponding critical value. In addition the narrowness of communication was estimated qualitatively on a scale of Cheddok.

Based on the presented initial data it is established that for a deviation of level of strategic productivity takes place significant rank of correlation communicate with indexes of achievement of planned targets on the following indicators presented in table 3.

Table 3. Results of rank correlation

\begin{tabular}{|c|c|c|c|c|c|c|}
\hline Display-indicators & Indicator & \begin{tabular}{|c|}
$\begin{array}{c}\text { Selective factor of } \\
\text { rank correlations } \\
\text { of Spirmen }\end{array}$ \\
\end{tabular} & \begin{tabular}{|c} 
Critical value of \\
distribution of \\
Spirmen
\end{tabular} & $\begin{array}{c}\text { Selective factor of } \\
\text { rank correlations } \\
\text { of Kendall }\end{array}$ & $\begin{array}{c}\text { Critical value of } \\
\text { distribution of } \\
\text { Kendall } \\
\end{array}$ & Character of correlation \\
\hline \multirow{3}{*}{$\begin{array}{c}\text { Consolidation and } \\
\text { development Gas } \\
\text { development actives }\end{array}$} & $\begin{array}{l}\text { Extent of served gas } \\
\text { pipelines }\end{array}$ & 0,59 & 0,46 & 0,45 & \multirow{4}{*}{0,36} & Is frugal, put-telnaja \\
\hline & $\begin{array}{c}\text { Registration of gas } \\
\text { pipelines in the property }\end{array}$ & 0,54 & 0,48 & 0,43 & & $\begin{array}{c}\text { Is moderated(moderate) } \\
\text { th, put-telnaja }\end{array}$ \\
\hline & $\begin{array}{l}\text { Total amount of } \\
\text { investments in actives } \\
\text { GDS under the } \\
\text { investment program }\end{array}$ & 0,91 & 0,23 & 0,83 & & High put-telnaja \\
\hline $\begin{array}{c}\text { Economilal effect of } \\
\text { actions }\end{array}$ & Net profit & 0,50 & 0,50 & 0,46 & & $\begin{array}{c}\text { Is moderated(moderate) } \\
\text { th, put-telnaja }\end{array}$ \\
\hline
\end{tabular}

Having kept as explaining factors only statistically significant indicators from tab.3, we receive compact model for an estimation of influence of separate indicators on level of strategic productivity. We will estimate further adequacy of offered model. As strategic productivity is estimated by quantity of points on a discrete scale it is necessary to refuse use of the criteria similar to criterion of Fisher, applicable for continuous random variables with the normal law of distribution. We will be limited to an estimation of a relative error.

Let's consider values of strategic productivity $U_{k}$ in two cases: $U_{k}-$ at the account of all known indicators, $\tilde{U}_{k}-$ at the account only statistically significant indicators. For an average relative error (4):

$$
A=\frac{1}{n} \sum\left|\frac{\widetilde{U}_{k}-U_{k}}{U_{k}}\right| \cdot 100 \%
$$

We receive value $A=8,6 \%$. Such accuracy is represented sufficient for the preliminary forecast of strategic productivity.

Thus, the combination of the expert strategic analysis spent in the form of strategic verification and use of simple mathematical models allows to lift scientifically-practical validity of strategic decisions. It underlines importance, methodology interdisciplinary synergetic approach and its theoretical bases for perfection of development of system of strategic management.

\section{Conclusion}

Introduction of system of an estimation of strategic productivity will allow to focus attention of a management of the organisations to the importance for economic efficiency of activity of such indicators as personnel development, increase of a technological level of manufacture, the size of technological losses of gas at its transportation. The publication of given results becomes good stimulus for investors, including foreign, and starting step to start the mechanism of the investment promoting the further development, both separate economic units, and corporation as a whole.

The methodological approach offered in work and the methodical toolkit directed on increase of efficiency of strategic management at the enterprises of the oil and gas industry can be used at formation of strategy of development in other industries, and quality management inclusion in structure of standard tools of management of the modern enterprises becomes effective way of reception of competitive parity or competitive advantages.

\section{References}

Grebinyak L. How to make your strategy work. Effective implementation of the strategy and the implementation of change. Dnepropetrovsk: Balance \& Buck. 2006, p. 3

Melnik, A.N., Mustafina, O.N. (2014). The liberalization of electricity market in the system of measures for improving industrial 
enterprisers competitiveness: The case of Russia. Mediterranean Journal of Social Sciences, 5 (18 SPEC. ISSUE), pp. 293-298

GOST R ISO 9000-2005 Quality Management System. Fundamentals and vocabulary

M. Coveney, Genster D., B. Hartley, King D. The strategic rupture. Technology incarnation of corporate strategy into reality. - M. Alpina, 2004. - p. 16

Lawrence G. Hrebiniak Major problems of execution strategies (Lawrence G. Hrebiniak), Making Strategy Work. - Wharton School Publishing, 2005

Methods of assessing the effectiveness of the QMS enterprises (organizations), the military-industrial complex. M .: VTS "Military Register", 2006

Melnik, A.N., Dyrdonova, A.N. (2014). Infrastructural support for development of the territorial petrochemical cluster. Mediterranean Journal of Social Sciences, 5 (18 SPEC. ISSUE), pp. 299-304.

General Theory of Statistics: A Textbook / Ed. corr. RAS II Eliseev. - 4th ed., Revised. idop - M .: Finance and Statistics, 2001. - 480 p.

Pronin Z.J. Managing the implementation of organizational strategy: Author. Dis. kand.ekon. Sciences. Moscow 2011

Tereshchenko N.V., Yashin N.S. The functioning of the QMS and its effectiveness // Methods of Quality Management. 2006. №4; // All about quality. 2008. Vol. 53. S. 88

Yashin N.S. Andreeva T.A. Methodology "Hocine kanri" in the strategic management of oil and gas corporation // Bulletin of the Saratov State Socio-Economic University. - Saratov. - 2013. - № 5 (49). - P. 116-123

Bodley-Scott S., Brache A. Implementation: how to transform strategic initiatives into blockbuster results. - N.Y .: McGraw Hill, 2008. - P. 34-35.

Melnik A.N., Ermolaev K.A., Antonova N.V.Stages in Formalizing Energy Conservation and Efficiency Management in Industrial Enterprises// Mediterranean Journal of Social Sciences.- Vol.5, No12, (2014)-pp.173 - 176. 